\title{
Performance of Horizontal Wells Completed in Unconsolidated Sand: Case Study Niger-Delta
}

\author{
Sunday Agbons Igbinere* Ikponmwosa Ohenhen \\ Department of Petroleum Engineering, University of Benin, PMB 1154, Benin City, Nigeria
}

\begin{abstract}
Drilling and completion of horizontal wells have been proven to be a productive and profitable project, in comparison with the performance of the conventional vertical wells. However, in Nigeria there are very few application of horizontal wells as open-hole, this is largely due to the unconsolidated nature of Niger-Delta sands. This study examined the completion of open-hole horizontal wells with a case study of a field which is located within the Niger-Delta region in Nigeria. Two (2) wells which have been successfully drilled and completed were sampled. To achieve this, the performance of the completion option was examined using an analytical approach. This implored the Joshi's model and Vogel's equation to construct the Inflow Performance Relationship (IPR) plot. The vertical lift performance (VLP) was considered by employing Gilbert's method. From the combined plots, the optimum operating condition of the wells indicated that well $\mathrm{A}$ has a productivity index of 1.039 $\mathrm{Stb} / \mathrm{day} / \mathrm{psi}$ with a maximum flow rate of $3250 \mathrm{Stb} /$ day, while well B has a productivity index of $1.156 \mathrm{Stb} / \mathrm{day} / \mathrm{psi}$ and maximum rate of $3370 \mathrm{Stb} /$ day. The results show that horizontal well projects executed in fields within the Niger-Delta region can be expected to produce at good rates as obtained in other regions of the world. With the production capacity shown by these wells, improved conventional ultimate recovery is assured.
\end{abstract}

Keywords: Horizontal Well, Inflow Performance Relationship, Open-hole, Productivity index, and Vertical Lift Performance.

DOI: $10.7176 / \mathrm{JEES} / 11-10-07$

Publication date:October $31^{\text {st }} 2021$

\section{Introduction}

Horizontal wells and multilateral wells are progressively being used for the production of oil and gas fields around the world. These horizontal wells have been defined as wells drilled parallel to the reservoir bedding plane; that is, the well has a maximum deviation from the vertical plane that ranges between $85^{\circ}-95^{\circ}$ (Joshi, 1991).A major advantage that horizontal completions present is that their long horizontal well section provides connectivity to non-connected porous zones in the reservoir which makes oil and gas production from such reservoirs possible. Joshi, (1986) stated that due to longer well length, in a given time period under similar operating conditions, a horizontal well would drain a larger reservoir area than a vertical well. This is practically possible because of the introduction of secondary permeability into the formation as a result of drilling into the formation. Pore spaces initially not connected can either be completely or partially isolated or connected to zones of high permeability, which may be vertical or horizontal permeability. The productivity of a horizontal well is two to five times more than the productivity of a vertical well and this improvement occurs because of the contact area between the reservoir and the well (Joshi, 1991). Nind, (1964) explained that the inflow performance relationship is typified, so far as the gross liquid production is concerned by the well's productivity index. He also stated that "if it is assumed that the IPR is a straight line, the productivity index J will define the formation's potentialities" i.e. the formation's maximum flow rate and static pressure. However, other models used in modeling two phase inflow performance due to the presence of gas areas proposed by (Vogel, 1968 and Fetkovich, 1973) and have been used to carry out studies on vertical well IPR. Several steady-state productivity index analytical solutions have been presented for horizontal wells. These solutions can be extended for both transient and pseudo steady-state conditions using concepts of drainage boundary expansion with respect to time, shape factors and effective wellbore radius, as well. Fourier's law and Ohm's law with Darcy's law equations have been tested with physical models (Joshi, 1987; and Freddy et al, 2004).

Horizontal wells are not only beneficial for improving productivity but also for the tremendous amount of information they provide (Azzouguen, 2000). This research has been prompted by a thought of an improved completion option for wells drilled in Niger-Delta, considering the unconsolidated nature of Niger-Delta sands. It is aimed at examine the performance of horizontal open-hole completions in the Niger-Delta, wherein the productivity index, the IPR, VLP and the optimum operating conditions were determined.

\section{Materials and Methodology}

The research design has a simple procedure for the estimation of the well performance that makes use of an analytical approach. The methodology is simply based on the conventional procedure of estimating a well's performance considering its inflow performance and vertical lift performance. In an attempt to achieve this, two wells were sampled in this research. The productivity indices of these wells were evaluated using the popular Joshi 
model for horizontal wells. The IPR was constructed using Vogel's model. The data are the pre-production test result of the wells as conducted immediately after completion. The wells' PVT properties as well as some reservoir properties like estimated permeability were known, and shown in Tables 1 through 3.

\subsection{Procedure for Models Application}

To estimate the result from this model, the following simple procedure was used:

1. Evaluate the horizontal drainage radius, $r_{e H}$, using Joshi's method illustrated in equation 3 assuming a 40 acres drainage area.

2. Estimate the value of the constant ' $a$ ' in the productivity index model.

3. Evaluate the well's productivity index, $J_{H}$ using equation

$$
J_{H}=\frac{0.007078 k_{o} h /\left(\mu B_{O}\right)}{\ln \left[\frac{a+\sqrt{a^{2}-(L / 2)^{2}}}{L / 2}\right]+\frac{h}{L} \ln \left(\frac{h}{2 r_{w}}\right)}
$$

4. Find the maximum flow rate (AOFP) using $q_{\max }=J_{H} \times P_{i}$

5. Prepare a table of flow rates and pressures $\left(\mathrm{P}_{\mathrm{wf}}\right)$ using Vogel's method.

$$
q_{o}=q_{\max } \times\left[1-0.2\left(\frac{P_{w f}}{P_{i}}\right)-0.8\left(\frac{P_{w f}}{P_{i}}\right)^{2}\right]
$$

6. From the table formulated in step 3, plot pressures $\left(\mathrm{P}_{\mathrm{wf}}\right)$ against flow rates on a Cartesian graph.

7. Using Gilbert's method, generate tables for the well's Vertical Lift Performance. Average tubing pressure values from pre-production test results was used as input THP.

8. From the table generated in step 5, plot pressures $\left(\mathrm{P}_{\mathrm{wf}}\right)$ against flow rate on the same graph.

9. Analyze the plots to determine the well's optimum operating condition and hence the optimum bottomhole flowing pressure and flow rate of the well. On completion of the analysis, the optimum operating conditions of the wells are analyzed.

\subsection{Models Application and Analysis}

The sourced data used for this research are presented in Tables 1 to 3, and were obtained from two different wells located in Niger-Delta.

\begin{tabular}{|c|c|c|c|c|c|}
\hline \multicolumn{6}{|c|}{ WELL A } \\
\hline $\begin{array}{l}\text { CHOKE SIZE } \\
\text { (1/64") }\end{array}$ & $\begin{array}{l}\text { FTHP } \\
\text { (PSI) }\end{array}$ & $\begin{array}{l}\text { FLP } \\
\text { (PSI) }\end{array}$ & $\begin{array}{l}\text { API } \\
\left({ }^{\circ}\right)\end{array}$ & $\begin{array}{l}\text { OIL RATE } \\
\text { (BOPD) }\end{array}$ & $\begin{array}{l}\text { BS\&W } \\
(\%)\end{array}$ \\
\hline 24 & 186 & 161 & 13.9 & 531 & $1 \%$ \\
\hline 28 & 182 & 177 & 14.8 & 511 & $1 \%$ \\
\hline 32 & 180 & 176 & 14.3 & 479 & $0 \%$ \\
\hline 36 & 152 & 147 & 13.3 & 728 & $0 \%$ \\
\hline 40 & 180 & 175 & 13.5 & 890 & $0 \%$ \\
\hline
\end{tabular}

Table 1: Pre-production data for well A

\begin{tabular}{|c|c|c|c|c|c|c|}
\hline \multicolumn{7}{|c|}{ WELL B } \\
\hline $\begin{array}{l}\text { CHOKE SIZE } \\
\left(1 / 64^{\prime \prime}\right)\end{array}$ & $\begin{array}{l}\text { FTHP } \\
\text { (PSI) }\end{array}$ & $\begin{array}{l}\text { FLP } \\
\text { (PSI) }\end{array}$ & $\begin{array}{l}\text { API } \\
\left({ }^{\circ}\right)\end{array}$ & $\begin{array}{l}\text { OIL RATE } \\
\text { (BOPD) }\end{array}$ & $\begin{array}{l}\text { GAS RATE } \\
(\mathrm{SCF} / \mathrm{D})\end{array}$ & $\begin{array}{l}\text { BS\&W } \\
(\%)\end{array}$ \\
\hline 16 & 55 & 20 & 17.00 & 220 & 0.0061 & 0 \\
\hline 20 & 40 & 26 & 17.60 & 212 & 0.0061 & 0 \\
\hline 24 & 37 & 20 & 17.50 & 240 & 0.0061 & 0 \\
\hline 28 & 17.5 & 12 & 17.60 & 240 & 0.0061 & 0 \\
\hline
\end{tabular}

Table 2: Pre-production data for well B 
Table 3: Reservoir properties of the wells

\begin{tabular}{|l|cc|}
\hline PROPERTIES & WELL A & WELL B \\
\hline Initial Pressure (psia) & 3110 & 2915 \\
Temperature ( ${ }^{\circ}$ F) & 148 & 138 \\
Api Gravity ( ${ }^{\circ}$ & 17.6 & 27.5 \\
Oil FVF (rb/stb) & 1.07 & 1.11 \\
Viscosity (cp) & 11.8 & 2.6 \\
Solution Gor (scf/stb) & 84 & 221 \\
Bp Pressure (psia) & 866 & 1440 \\
Thickness (ft) & 32 & 25 \\
Length (ft) & 1438 & 1174 \\
Well Radius (ft) & 0.229 & 0.229 \\
Tubing Size (in) & 3.5 & 3.5 \\
Permeability (md) & 87 & 30 \\
\hline
\end{tabular}

First, we consider the horizontal drainage radius for both wells by applying existing models as stated in equations 2.3 through to 2.5 .

$$
\begin{aligned}
& r_{e H}=\frac{L}{2}+r \\
& A=\pi r^{2}
\end{aligned}
$$

Where $\mathrm{A}$ is drainage area in acres, $\mathrm{r}$ is the radius in $\mathrm{ft}$. and $\mathrm{L}$ is the length of the horizontal well in $\mathrm{ft}$. While equation 6 (Vogel's model) was used to generate the IPR plot and one case was presented for each well. The same procedure is used for the remaining unknown values.

$$
\begin{aligned}
& \qquad a=\left[\frac{L}{2}\right]\left[0.5+\sqrt{0.25+\left(2 * r_{e H} / L\right)^{4}}\right]^{0.5} \\
& \qquad \frac{q_{o}}{q_{o \max }}=\left[1-0.2\left(\frac{P_{w f}}{P_{s}}\right)-0.8\left(\frac{P_{w f}}{P_{s}}\right)^{2}\right] \\
& \text { Where } \quad q_{o}=\text { oil flow rate, stb/day } \\
& q_{o \text { max }}=\text { maximum flow rate for } 100 \% \text { drawdown, stb/day } \\
& P_{S}=\text { shut-in pressure or average reservoir pressure, psi } \\
& P_{w f}=\text { bottom-hole flowing pressure, psi }
\end{aligned}
$$

\begin{tabular}{|c|c|c|c|}
\hline $\mathbf{S} / \mathbf{N}$ & Parameters & Well A & Well B \\
\hline 1 & Length L (ft) & 1438 & 1174 \\
\hline 2 & Drainage Area A (acres) & 40 & 40 \\
\hline 3 & Radius $\mathrm{r}(\mathrm{ft})$ & 745 & 745 \\
\hline 4 & Horizontal Drainage Radius $\mathrm{r}_{\mathrm{eH}}(\mathrm{ft})$ & 1464 & 1332 \\
\hline 5 & Productivity Index $J_{H}(\mathrm{stb} /$ day/psi) & 1.039 & 1.156 \\
\hline 6 & Maximum flowrate $\mathrm{Q}_{\max }$ (stb/day) & 3250 & 3370 \\
\hline 7 & Optimum flowrate ( $\left.\mathrm{Q}_{\text {opt }}\right)$ (stb/day) & 1130 & 1925 \\
\hline 8 & Optimum flowing bottom-hole pressure $\left(\mathrm{FBHP}_{\mathrm{opt}}\right) \mathrm{psi}$ & 2420 & 1800 \\
\hline
\end{tabular}

To estimate the VLP using Gilbert's approach, the average tubing head pressures from the pre-production test results were used as input pressure. For well A, this pressure is 176 psi and for well B, its 38 psi.

\section{Results and Discussion}

The following are the results obtained.

Table 4: Summary of reservoir and well results from wells A and B

Table 5: Vertical lift performance data for the wells using Gilbert's method

\begin{tabular}{|c|c|c|c|c|c|c|}
\hline \multicolumn{7}{|c|}{ WELL A } \\
\hline Qo (b/d) & DTHP (ft) & DBHP (ft) & BHP (psi) & DTHP (ft) & DBHP (ft) & BHP (psi) \\
\hline $\mathbf{5 0}$ & 650 & 9130 & 2750 & 300 & 8300 & 2360 \\
$\mathbf{1 0 0}$ & 500 & 8980 & 2640 & 230 & 8230 & 2170 \\
$\mathbf{2 0 0}$ & 700 & 9180 & 2550 & 160 & 8160 & 1950 \\
$\mathbf{4 0 0}$ & 720 & 9200 & 2520 & 100 & 8100 & 1800 \\
$\mathbf{6 0 0}$ & 750 & 9230 & 2500 & 80 & 8080 & 1750 \\
\hline
\end{tabular}




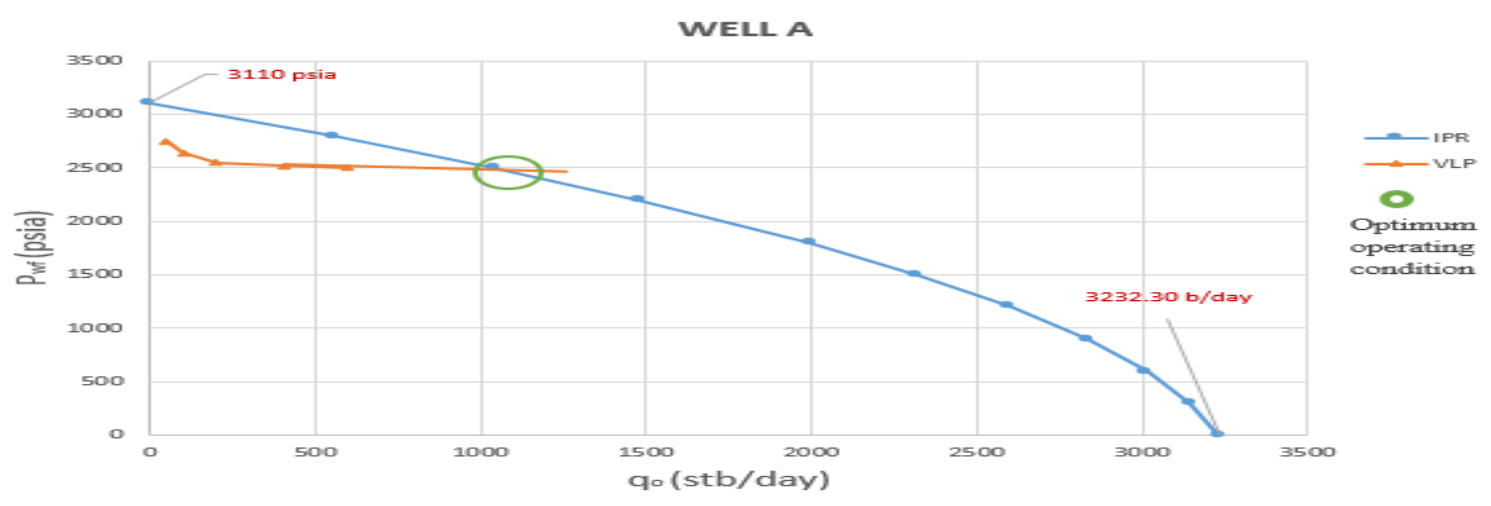

Figure 1: Performance plot for well A

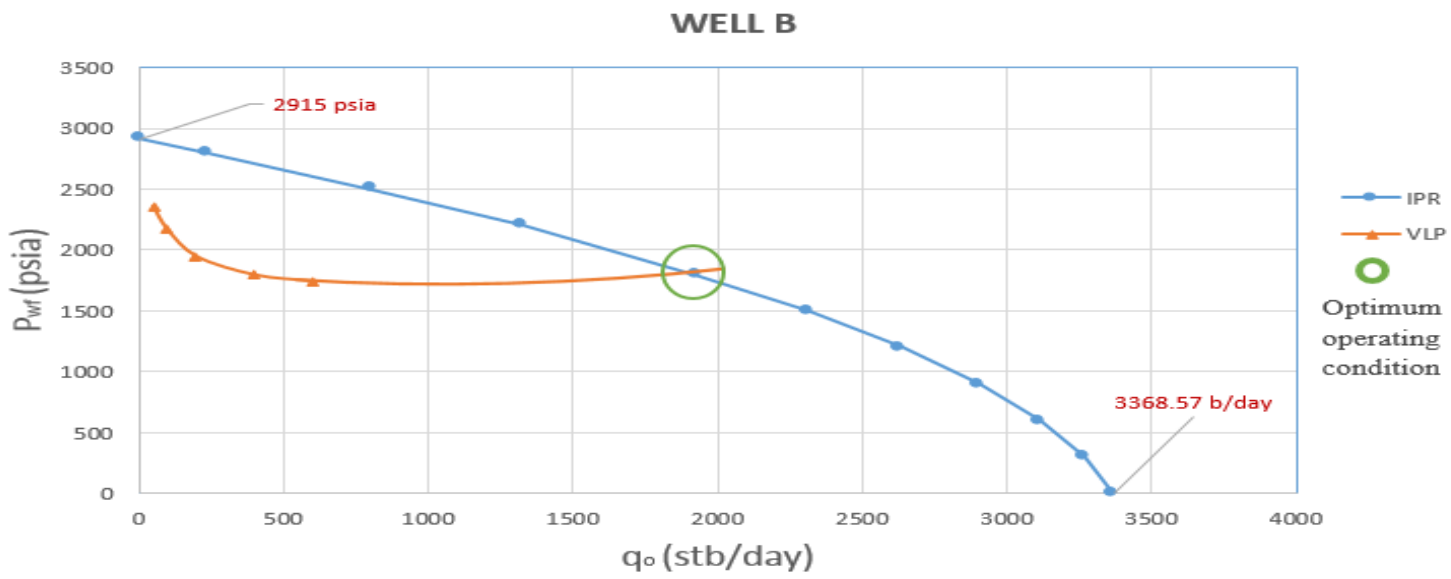

Figure 2: Performance plot for well B

The wells are producing at pressures and flow rates that will allow continues flow of reservoir fluids to the wellbore and up to the surface, this is obvious from the results presented in Figures 1 and 2 and Tables 4 and 5, as the IPR continues to shift downward due to depletion of the reservoir as the relative permeability to gas saturation increases. It was observed that well $\mathrm{A}$ has a productivity index of $1.039 \mathrm{stb} / \mathrm{day} / \mathrm{psi}$ and is expected to flow at a maximum flow rate of $3250 \mathrm{stb} /$ day, while well $\mathrm{B}$ has a productivity index of $1.156 \mathrm{stb} / \mathrm{day} / \mathrm{psi}$ and is expected to flow at a maximum flow rate of $3370 \mathrm{stb}$ /day. The performance plots revealed that well $\mathrm{A}$ has an optimum operating condition (indicated by the green circle) of 1130 barrels of oil per day with a flowing pressure at the sand face of 2420 psi. Well B also shows similar high performance, with an optimum operating condition of 1925 barrels of oil per day and 1800 psi of pressure at the sand face.

In Figures 1 and 2, the IPR shows a curve which is noted to have started at a point close to the bubble point pressure of the well in each case. This follows Vogel's theory for the inflow performance plots. This curvature appears as a result of the release of a more compressible phase (gas) from the far less compressible phase (oil) which dominates production before the bubble point is reached. One easy way of noticing that this point has been reached is the gradual increase in gas-oil ratio. The vertical lift performance carried out for these wells using Gilbert's method yields a plot which is extrapolated to meet the inflow performance plot so as to obtain the optimum operating conditions for the wells. Gilbert's work was originally conducted using vertical wells and such high values of flow rate were not anticipated, and it is the most common method for determining the vertical lift performance of a producing well. However, this work adopted this approach in horizontal wells and high values of flow rates were obtained in both wells with well B resulting from a lower flowing bottom - hole pressure.

Both the inflow performance plots and the vertical lift performance plots show that there exists an inverse relationship between the flow rate and pressure at the sand face of a well. In order words, the flow rate increases as the pressure at the sand face decreases. However, it is important to mention that the vertical lift performance can in some cases show a direct relationship at some points as is shown by the curved portion of the plot for well B. But in this study, the curvature does not appear to remain for long as it has a gradually decreasing moderate slope.

\section{Conclusion}

Based on the results obtained from this study, we infer that:

1. Horizontal well projects executed in fields within the Niger-Delta region can be expected to produce good 
results as obtained in other regions of the world.

2. Gilbert's method can effectively be applied in horizontal wells completed in unconsolidated formations in Niger - Delta.

3. With the production capacity shown by these wells, improved conventional ultimate recovery is assured.

\section{Recommendation}

Further study in this area should be conducted with the aim of estimating the effect of skin and reservoir heterogeneity and also the economic analysis of this completion option given the prevailing conditions in the Niger-Delta.

\section{Acknowledgement}

The authors acknowledge the immense contribution of G.. O. Bello-Ososo of the Department of Petroleum Engineering, University of Benin, Benin City, Nigeria, during this research work.

\section{References}

Azzouguen, A., Mazouzi, A., Delhomme, A. and Deghmoum, A. (2000), "Horizontal Well Performances inHassiMessaoud Oil Field, Algeria”.Paper SPE 65496, SPE/Petroleum Society of CIM Inter-National Conference on Horizontal Well Technology, 6-8 November, Calgary, Alberta, Canada

Fetkovich, M.J. (1973), “The Isochronal Testing of Oil Wells”. Paper SPE 4529, SPE 48thAnnual Fall Meeting, Sept. 30 - Oct. 3, Las Vegas, Nevada.

Freddy, H. E. and Surcolombiana, U., Nestor, F. E., Ecopetrol-ICP, Robin F. A. and John F.H. (2004), "An Improved Correlation to Estimate Productivity Index in Horizontal Wells". Paper SPE 65507, SPE Asia Pacific Oil and Gas Conference and Exhibition, $18^{\text {th }}-20^{\text {th }}$ October.

Joshi, S. D. (1987), "A Review ofThenna1 Recovery Using Horizontal Wells".Journal paper 11, Nos. 2 and 3, pp. 211-59.

Joshi, S.D. (1986), “Augmentation of Well Productivity with Slant and Horizontal Wells”.Paper SPE 15375, SPE Annual Technical Conference and Exhibition, Oct 5-8, New Orleans.

Joshi, S.D. (1991), "Horizontal Well Technology” Joshi Technology International, Inc. Tulsa, OK, U.S.A.

Nind, T.E.W. (1964), "Principle of Oil Well Production". A Book Published in McGraw - Hill Book Company, New York, USA.

Vogel, J.H. (1968), "Inflow Performance Relationship for Solution-Gas Drive Wells". Journal of Petroleum Technology, pp. 83-92. 